\title{
Impact of nutrition on muscle mass, strength, and performance in older adults: response to Scott and Jones
}

\author{
A. Mithal • J.-P. Bonjour • B. Dawson-Hughes • \\ for the IOF CSA Nutrition Working Group
}

Received: 27 May 2013 / Accepted: 14 June 2013 / Published online: 21 September 2013

(C) International Osteoporosis Foundation and National Osteoporosis Foundation 2013

Dear Editor,

We would like to thank Drs. Scott and Jones [1] for the interest shown in our manuscript.

The data presented by them further underscore the importance of nutrition in determining and maintaining muscle mass in older adults. We agree with the authors about the need for clinical trials to study the effects of intervention with various dietary nutrients in reducing and preventing sarcopenia.

\section{References}

1. Scott D, Jones G (2013) Impact of nutrition on muscle mass, strength, and performance in older adults. Osteoporos Int. doi:10.1007/s00198013-2510-7

A. Mithal $(\bowtie)$

Medanta Medicity, Gurgaon, Haryana, India

e-mail: ambrishmithal@hotmail.com

J.-. P. Bonjour

Division of Bone Diseases, University Hospitals and Faculty of

Medicine, Geneva, Switzerland

B. Dawson-Hughes

USDA Nutrition Center, Tufts University, Medford, MA, USA 